\title{
A Simulation Model for Sprinklers Irrigation System
}

\author{
D.O.I - 10.51201/Jusst12559 \\ http://doi.org/10.51201/Jusst12559 \\ Naglaa Ragaa Saeid Hassan \\ Associate Professor - Dept. of Operations Research and Management, Faculty of Statistical \\ Studies and Research, Cairo University, Egypt.
}

\begin{abstract}
Center pivot irrigation (CPI) system is one of the most efficient methods of applying irrigation water. It is a form of overhead sprinklers irrigation supported by trusses. The sprinkler flow rate out of each sprinkler orifice is based on the water pressure supplied to the sprinkler inlet. The objective of this paper is to build a simulation model for CPI to optimize performance of system estimating the expected number of a sprinklers and diameter of nozzle according to the required water quantities.
\end{abstract}

\section{Keywords: Irrigation districts, Water management, Reservoir management, simulated center pivot irrigation model, expected number of sprinklers, diameter of nozzle}

\section{Introduction}

Operations research (OR) helps decision makers in taking the decision based on information and the main objective of OR is to utilize limited resource for more benefits. Simulation models as one of OR tools help decision makers to develop simulators looking for improvement, testing and establish the bottom line for the improvement idea that are being made. The major factor of agricultural systems is water. To sustain agricultural production in the coming years, it is important to optimize irrigation systems, adjusting water application according to crop water requirements. This will help protect both the qualitative and quantitative aspects of water conservation. CPI contains sprinklers joined together and supported by trusses moving in a circular pattern feeding with water. The system is already used in parts of the United States, Australia and also in desert areas such as the Sahara and the Middle East. In the last decades, different approaches are used to simulate the processes characterizing an irrigated area. In this paper, the center pivot simulation model is applied to improve the performance of existing irrigation system or to design new systems. The objective of this paper is to build a simulated model of CPI to optimize the performance of system estimating the expected number of sprinklers and diameter of nozzle. This paper is as follows: Section 2 presents "Literature Review about Optimization Techniques in Irrigation systems". Section 3 considers "Methodology" showing the steps of building simulation model for irrigation system. Section 4 introduces "The details of proposed computerized irrigation simulation model" which explain the details about the input, processing and output units. Finally Section 5 presents "Conclusion".

\section{Literature Review about Optimization Techniques in Irrigation Systems}

Figure 1 shows the fields of circles created by the watery tracings of "quarter- or half-mile of the center-pivot irrigation pipe, created by center pivot irrigators which use "hundreds and sometimes thousands of gallons a minute. The advantages of CPI systems are capabilities to prescribe the volume of water to match crop water requirements, the labor requirements are lower than surface irrigation and a system allows small quantities of nutrient (less risk of nutrient losses). The sprinklers flow rate out of each sprinkler orifice is based on the water Pressure supplied to the sprinkler inlet as in Figure 1. 


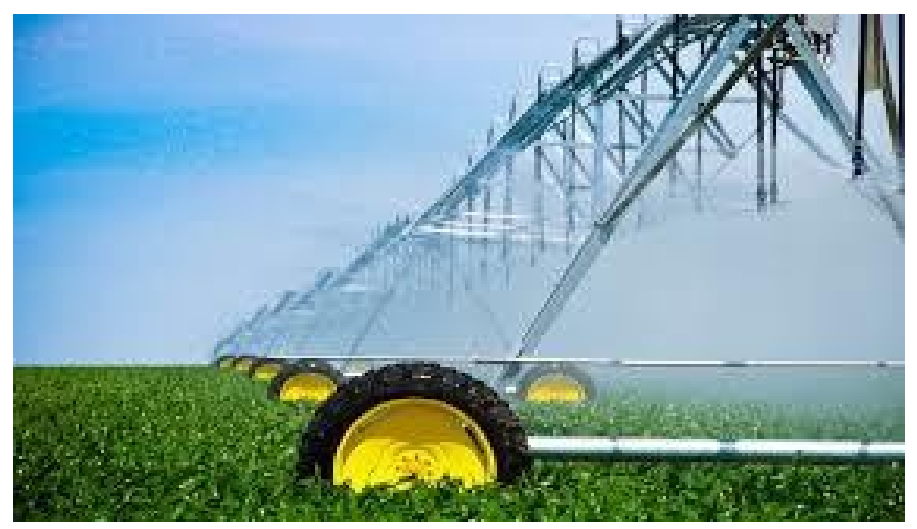

Figure 1. Towers of Pivot \& sprinklers

CPI simulation models are used to modify existing systems improving irrigation performance and to design the new systems. Since the 1960s, the subject of simulation of center pivot performance has been a series of research efforts. [1] considered a simulated model of CPI model with objective of defining the optimal sprinkler spacing to obtain uniform distribution of water. [2] continued this line of research taking in their account the overlapping effect of neighboring sprinklers and introduced the uniformity coefficient. In (1993), [3] developed the CPI software model for water and / or water-nitrate distribution. [4] developed a simulation model of water application focusing on irrigation uniformity. A software package of CPI evaluation and design (CPED) was introduced by [5]. [6] improved a model for optimal allocation of water to competing demands using two optimization techniques, i.e. weighting technique and simultaneous compromise constraint technique. The model was capable of allocating water among six sectors with maximizing either satisfaction or net economic return or both. Applying new technologies to irrigation water management leads to improvements in the productivity and sustainability of agricultural systems. [7] conducted an interesting study by combining remote sensing simulation model and genetic algorithm (GA) to discover water management option in irrigated agriculture. Results show that adjusting sowing date and distribution with deficit irrigation, can improve regional yield. [8] used GA for optimizing water delivery program. They found that GA is useful for water distribution problem in irrigation channels. [9] employed evolutionary optimization technique to find a near optimal solution for problem within reasonable computational time. The obtained results compared with complex evolution algorithm, optimization algorithm, simulated annealing and differential evolution. The new tool developed shows striking superiority over the existing optimization techniques. [10] conducted a study to optimize problem of cost for drip irrigation system using GA. The results show that there improvement in the calculation runtime and in cost of drip system, as compared to other models available. [11] developed a model based on dynamic optimization model for managing and optimizing multiple resources for irrigation and fisheries. [12] developed an algorithm using a particle swarm to optimize irrigation tree pipe networks layout and size. They compared the results to GA and they observed a quick response from their model with an increase in search space compared with GA. [13] applied Harmony search optimization technique for identifying optimal pipe size in looped irrigation water supply system. They developed an algorithm to find out the optimal costeffective of pipe diameter for irrigation system and they applied to real life problems. It shows more promising than others available models. [14] identifying optimal irrigation water needs at district scale by using a physically based agro-hydrological model.

\section{Methodology "Simulation Model"}

Simulation is widely used OR and management science techniques. Simulation models as one of OR tools help decision makers to develop simulators looking for improvement, testing and establish the bottom line for the improvement idea that are being made. A simulation is the copy of the operations of a real-system or process. It is based on the generation of an artificial history of a system to draw inferences depending on the characteristics of real system. A primary benefit of simulation analysis is that it enables us to experiment with the model. 


\subsection{Steps of building the Simulation model for irrigation system}

Problem Definition: it is a first step where the situation must be studied and identified the problem precisely to understand the fundamental questions clearly. So, at this stage, we have to determine the problem's objective and decide on the problem's classification such as deterministic or stochastic. In our presented problem, we have to determine the optimal rationalization of water resources through the identification location of sprinklers along the irrigation system according to specific factors and inputs such as the amount of water, pressure and land area through the design of system.

Project Planning: Before developing a simulation model, it must identify what is to be simulated and how the resulting data will be used. Many additional details must be addressed as well. There must be a simulation software development process that deals with issues, in our presented problem; we need to determine the optimal distribution of the location of the sprinklers length pivot and its numbers. Designing a simulation model includes the definition of input data sets, and how simulation output data is analyzed and used as input for a sprinklers programming.

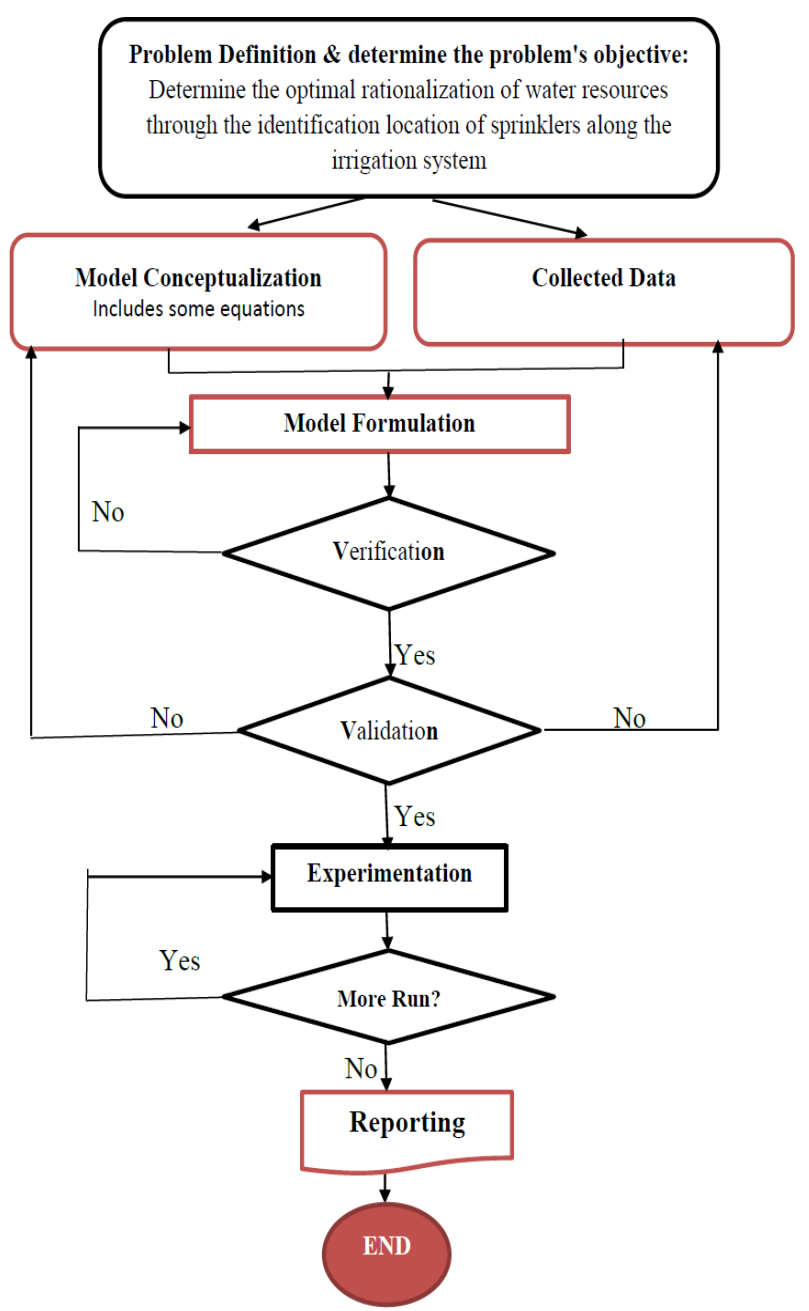

Flowchart 1 The proposed simulation model for system Irrigation

System Definition: After completion of the simulation, the main purpose of the system is to avoid the installation of sprinklers at fault locations along the pivot where the locations of these sprinklers are determined according to specific criteria in the form of mathematical and physical equations.

Model Formulation: This is the stage in the modeling process where we creates a mathematical equations representation of a conceptual model Is consistent with the problem under study where these equations were formulated in the code of the system in which we designed for this purpose. 
Input Data Collection \& Analysis: There is no doubt that The main source of data in this field is the agricultural companies where we collected the data from the specialists and were analyzed and indexed by nature and priority use to obtain the required outputs.

Model Formulation: Both of input and output of the simulator are designed in the input screens and output screens that the user can easily handle during the input and get information from the system.

- $\quad$ Verification \& Validation: At this stage, the results or outputs are tested to ensure of its validity and compliance with the actual outputs of other systems.

- Experimentation: The outputs are validated and the suggested model is implemented in many agricultural companies. The simulation model for irrigation system is as shown in Flow chart 1.

\section{The details of proposed computerized irrigation simulation model}

The input stage: This stage contains two kinds of data, collected data (scheduling of nozzles) including number of nozzles, distance between nozzles, interval diameter, pressure at the ending of water flow from the well "Last nozzle".....etc. as in Figure 2. The second kind of data represents the model conceptual which includes the mathematical equations as the results of these calculations as shown in Figure 3. as input).

Figure 2 consists of seven columns; each one depends on the other in previous step (or column

Column 1: "The number of nozzle" which represents the number of nozzles distributed over the total length of the towers.

Column 2: "The distance between nozzles" which it is determined based on the design of the hub manufacturer.

Column 3: "The distance from Center" represents the distances between the nozzles and from the center.

Column 4: "The flow of nozzle" - its value through the following calculation

The flow of nozzle $=(2 *$ distance from center $*$ distance between nozzle $*$ water quantity $) \div$ (total area per square meters)

Column 5: "The flow of all pivots"- which use the following calculation:

The flow from all Pivots $=\left(\right.$ water quantity $*\left(1-(\text { distance from center })^{\wedge} 2\right) \div($ total area per square meters)

Column 6: "Pressure of nozzle / $\mathrm{m}$ " - its calculations as follows:

Pressure of nozzle $/ \mathrm{m}=\mathrm{HO}+($ friction Loss $) *(1-(15 / 8) *(($ distance From Center $\div$ length $)$ $\left((2 / 3)^{*}(\text { distance from center } \div \text { length })^{\wedge} 3\right)+\left((1 / 5)^{*}(\text { distance from center } \div \text { length })^{\wedge} 5\right)$

Column 7: "Diameter of nozzle" which depends on the results of previous columns and the type of nozzles according to the manufacturer

\section{Conceptualization model:}

After the completion of the first step of data entry, the second step in which the processing of the data entered by the user through a set of codes which contains of mathematical and physical equations as illustrated below.

Water Quantity: The water quantity flows to the pivot at the circle. The user enter the water quantity which out of the pump unit gallon per minute for the system to be converted to another unit, a liter per second to match the mathematical equations carried out by the system, On the other level, it was converted to a gallon unit per minute per hectare to determine the total amount of water per hectare as in Figure 3. 


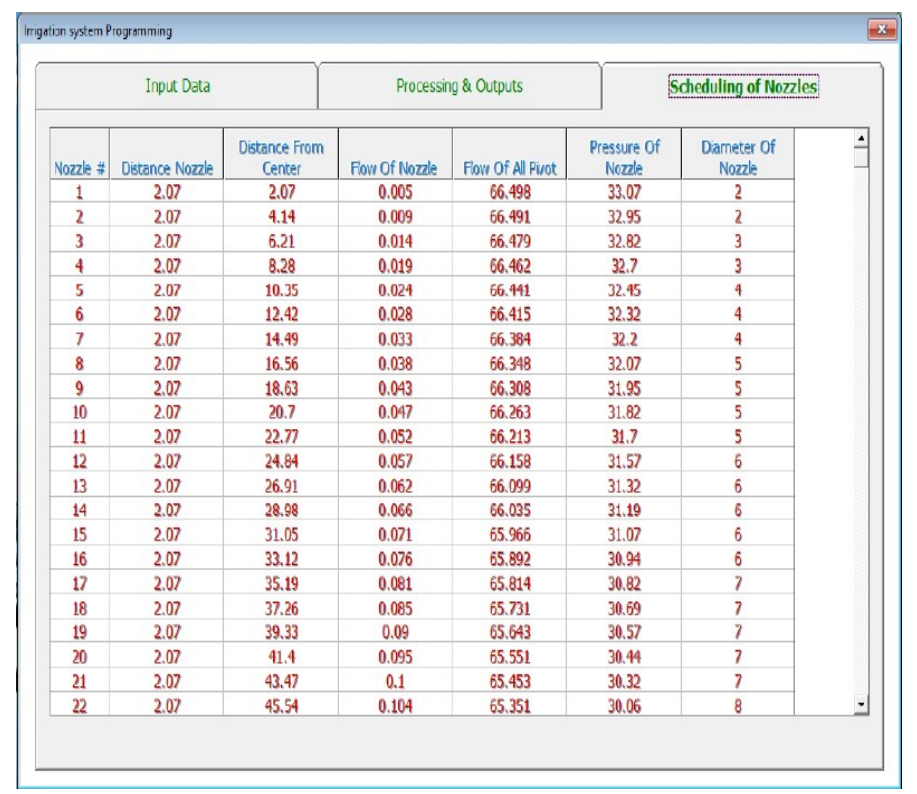

Figure 2. Collected Data as scheduling

Water Quantity $\mathbf{L} / \mathbf{S e c}=$ Water quantity $\mathrm{G} / \mathrm{M} \div(15.85)$

Water Quantity G/ M / Hectare = Water quantity G/M $\div$ Total Area / Hectare

Total length of towers $=$ Number of towers $*$ Length of tower

Total nozzle $=$ Number of nozzle for tower $*$ Number of towers

Total Distance between nozzles $=$ Distance between nozzles $*$ Total nozzles

Friction Loss: This can be calculated by the physics equation [9]

Total Area $/$ Hectare $=\left(\left(\left(\right.\right.\right.$ Total length of towers $\left.\left.\left.{ }^{\wedge} 2\right) * 3.14\right) / 10000\right)-\left(\left(\left(38.5^{\wedge}{ }^{\wedge} 2\right) * 3.14\right) \div 10000\right)(9)$

Total area per square meters $=\left(\right.$ Total length of towers $\left.{ }^{\wedge} 2\right)$

In the previous screen the user enters the data as referred before and save it as temporary in memory to go the second step in the system is to process this data to get the information.

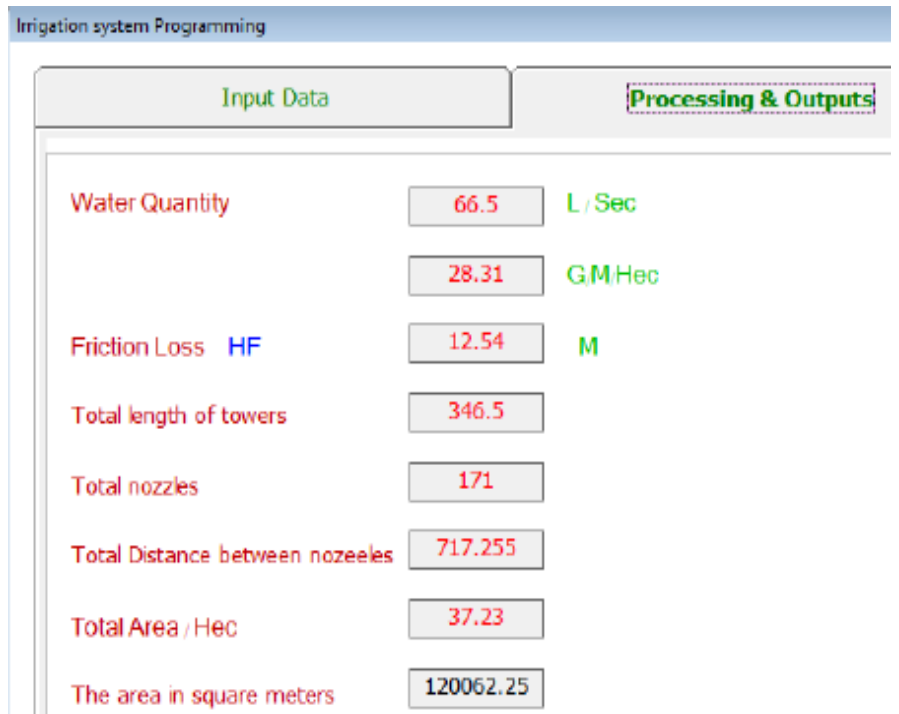

Figure 4. The outputs and information of data processing 
The results or outputs are shown as in Figure 4 which include:

- A Total area of pivot/Hectare

- A Total number of nozzles to be added to the pivot.

- The Total length of pivot towers.

- Water quantity liter/sec.

- Quantity of water Gallon/Meter/Hectare

\section{Analysis and discussion:}

The major factor of agricultural systems is water. It is important to optimize irrigation systems, adjusting water quantities for crop according to its requirements. According to initial information about scheduling of nozzles as in Figure 2 and the requirements of irrigation system as in Figure 3 which it shows that depending on available water quantity, number of towers, number of nozzle for tower, distance between nozzles, pressure and internal diameter of mother pipe, the program or simulated model determine the water's quantity which coming out Gallon/Min, reaching to the results as in Figure 4.

Table 1. The summary of Inputs/ Outputs of presented example

\begin{tabular}{|l|l|}
\hline \multicolumn{1}{|c|}{ Input } & Data \\
\hline Water Quantity G/M & 1054 \\
\hline Number of towers & 9 \\
\hline Length of tower & 38.5 \\
\hline Number of nozzle for tower & 19 \\
\hline Distance between nozzles & 2.07 \\
\hline Pressure HO Output & 20.66 \\
\hline Internal Diameter of mother pipe M/M & 150.6 \\
\hline & Info \\
\hline Water Quantity L / Sec & 66.5 \\
\hline Water Quantity G/M/Hec & 28.31 \\
\hline Friction Loss HF & 12.54 \\
\hline Total length $\quad 346.5$ \\
\hline Total sprinklers & 171 \\
\hline Total area & 37.23 \\
\hline
\end{tabular}

Thus, Table 1 shows the summary of presented example. When the water quantity for example $1054 \mathrm{G} / \mathrm{M}$, the No. of towers $=9 \ldots$...and .... so on Then, the total sprinklers 171 with total length 346.5 and the water quantity will be $66.5 \mathrm{~L} / \mathrm{sec}$. to cover 37.23 Hectare (or 120062 in square meters). An optimization model is applied to determine the optimal management strategy for use of reservoir water

\section{Conclusion}

This paper concentrates on building a simulation model for central pivot irrigation system to improve system performance determining the expected number and optimum distribution of sprinklers locations where improper installation of sprinklers in an unsuitable location causes damage to crops and wastewater resources.

The program gives the total expected nozzles, total length of tower and quantity of water needed that can irrigate the whole area at a time. The programming proves that the technology can assist in planning, managing and using irrigation system efficiently. Thus, irrigation system design and management can be easily modeled and controlled using computer software. The use of computer simulation models to predict the behavior of agricultural systems is a growing area of research. The use of computer simulation models may significantly enhance understanding of different ecosystems. 


\section{References}

[1] M. W. Bittinger and R. A. Longenbaugh, Theoretical distribution of water from a moving irrigation sprinkler , Trans. Amer. Soc. Agric. Eng. 5(1): 26-30, (1962).

[2] D. F. Heermann and P. R. Hein, Performance characteristics of self-propelled center pivot sprinkler irrigation system, Trans, ASAE, 11(1), 11-15, (1968).

[3] R. G. Evans, S. Han, L. G. James and M. W. Kroeger, CPIMA computer simulation program for center pivot irrigation systems; ASAE Paper No. 93-3065. St. Joseph, MI, USA: ASAE. (1993)

[4] B. Bremond and B. Molle, Characterization of rainfall under center-pivot: influence of measuring procedure". Journal of Irrigation and Drainage Engineering: ASCE, 121(5): 347-353, (1995).

[5] D. F. Heermann and K. Stahl, Center pivot evaluation and design package (CPED) - Users' manual, Ft. Collins, CO, USA: USDA-ARS-NPA-WMU, (2004)

[6] M. S. Babel, A. D. Gupta \& D. K. Nayak, A model for optimal allocation of water to competing demands, Water resources management 19: $693-712$, (2005)

[7] A. V. M. Ines, K. Honda, A. D. Gupta, P. Droogers, R.S. Clemnte, Combining remote sensing simulation modeling and GA optimization to explore water management options in irrigated agriculture. Agricultural water management, 83. Elsevier Science Publications (2006)

[8] R. M. Bagher and J. Pyman, Water delivery optimization program, of Jiroft dam irrigation networks by using GA, Int. J. Advance. Soft Comput. Appl., Vol 1, No.2. (2009).

[9] N. Shutze, T. Wohling, M. D. Paly and G. H. Schmitz, Applications of Evolutionary Computing, EvoWorkshops 2009: Germany, April 15-17, Proce; 01/(2009).

[10] M. S. Pais, J. C. Ferreira, M. B. Teixeira, K. Yamanaka, and G. A. Carrijo, Cost optimization of localized irrigation system using Genetic algorithm. 11th International Conference, Paisley, UK, September 1-3, Proceedings. Intelligent Data Engineering and Automated Learning - IDEAL (2010)

[11] L. Tran, S. Schilizzi, M. Chalak, and R. Kingwell, Managing multiple use resources: optimizing reservoir water use for irrigation and fisheries, 55th Annual AARES Nastional Conference, Melbourne, Victoria, Feb (2011).

[12] I. Mtolera, L. Haibin, L. Ye, S. B. Feng, D. Xue, and M. Yi, Optimization of tree pipe network layout and size, using Particle swarm optimization. WSEAS Transection on Computers. Vol 13 (2014).

[13] _D. G. Yoo, H. M. Lee, A. Sadollah, \& J. Kim, H. Optimal Pipe Size Design for Looped Irrigation Water Supply, The Scientific World J. V 2015, Article 651763, 10 pages http://dx.doi.org/10.1155/2015/651763 (2015).

[14] A. Coppola, G. Dragonetti, A. Sengouga, N. Lamaddalena, A. Comegna, A. Basile, N. Noviello, and L. Nardella, Identifying Optimal Irrigation Water Needs at District Scale by Using a Physically Based AgroHydrological Model, Water 2019, 11, 841 P:1:25 (2019) 